\title{
A atuação do nutricionista nas compras da agricultura familiar para o Programa Nacional de Alimentação Escolar em municípios do Rio Grande do Sul
}

\author{
Caroline Leitzke Renner Gallicchio ${ }^{1}$, Luciana Dias de Oliveira ${ }^{2}$, Gabriela Rodrigues \\ Bratkowski ${ }^{3}$, José Tobias Marks Machado ${ }^{4}$, Amália Leonel Nascimento ${ }^{5}$ e Vanuska \\ Lima da Silva ${ }^{6}$
}

Em 2009, a Lei no 11.947 estabeleceu que as Entidades Executoras do Programa Nacional de Alimentação Escolar (PNAE) usem no mínimo 30\% dos recursos repassados pelo Fundo Nacional de Desenvolvimento da Educação na aquisição de alimentos da Agricultura Familiar (AF), sendo uma das atribuições dos nutricionistas do PNAE participar desse processo. Este artigo objetiva analisar a atuação do nutricionista na viabilização da compra de alimentos da AF em municípios gaúchos com dificuldade para cumprir a legislação. Estudo quantitativo descritivo com utilização de dados secundários de questionário respondido por nutricionistas de 28 municípios do Rio Grande do Sul em 2018. Constatou-se que o Quadro Técnico de nutricionistas é insuficiente em 82,1\% dos municípios; 78,6\% dos nutricionistas acessaram o mapeamento agrícola local durante a elaboração dos cardápios; 85,7\% dos nutricionistas acompanham o processo de compras dos produtos da AF; 71,4\% dos municípios fazem reuniões de articulação com os agricultores familiares. Evidencia-se a necessidade de estudos mais detalhados que avaliem o engajamento e a qualidade das atividades realizadas pelos nutricionistas no processo de compras da $\mathrm{AF}$ para o PNAE.

Palavras-chave: Nutricionistas, agricultura familiar; Alimentação escolar; Programas e Políticas de nutrição e alimentação; Segurança Alimentar e Nutricional.

\footnotetext{
1 Mestranda da Universidade Federal do Rio Grande do Sul (UFRGS), Programa de Pós-Graduação em Desenvolvimento Rural. Nutricionista colaboradora no Centro Colaborador em Alimentação e Nutrição Escolar da Universidade Federal do Rio Grande do Sul (CECANE/UFRGS). E-mail: carolinegallicchio@gmail.com. ID ORCID: https://orcid.org/0000-0002-04424834. Endereço para correspondência: Rua Cândido Silveira no 213 - CEP: 90540-010 - Porto Alegre - RS - Brasil.

2 Professora Associada da Universidade Federal do Rio Grande do Sul (UFRGS), Faculdade de Medicina, Departamento de Nutrição. Coordenadora de Gestão do Centro Colaborador em Alimentação e Nutrição Escolar da Universidade Federal do Rio Grande do Sul (CECANE/UFRGS). E-mail. dialu73@hotmail.com. ID ORCID: https://orcid.org/0000-0002-3438-0668

3 Nutricionista mestra em Saúde Coletiva (Universidade do Vale do Rio dos Sinos - UNISINOS), colaboradora no Centro Colaborador em Alimentação e Nutrição Escolar da Universidade Federal do Rio Grande do Sul (CECANE/UFRGS).E-mail: gabriela.brat@gmail.com. ID ORCID: https://orcid.org/0000-0001-6170-5029

4 Professor Adjunto da Universidade Federal Rural da Amazônia (UFRA), Campus Parauapebas. E-mail: tobias.machado@hotmail.com. ID ORCID: https://orcid.org/0000-0002-1725-7166

${ }^{5}$ Nutricionista doutora em Desenvolvimento Rural (Universidade Federal do Rio Grande do Sul - UFRGS), colaboradora no Centro Colaborador em Alimentação e Nutrição Escolar da Universidade Federal do Rio Grande do Sul (CECANE/UFRGS).E-mail: amalialeonel@gmail.com

${ }^{6}$ Professora Associada da Universidade Federal do Rio Grande do Sul (UFRGS), Faculdade de Medicina, Departamento de Nutricão. Coordenadora de Gestão Substituta do Centro Colaborador em Alimentação e Nutrição Escolar da Universidade Federal do Rio Grande do Sul (CECANE/UFRGS). E-mail: vanuskal@yahoo.com.br. ID ORCID: https://orcid.org/0000-0002-74824489
} 


\section{The role of the nutritionist in the food purchases from family farming for the National School Feeding Program in municipalities of Rio Grande do Sul}

In 2009, the Law no 11.947 established that entities responsible for the execution of the National School Feeding Program (PNAE) should use at least 30\% of the resources transferred by the National Fund for Educational Development to purchase food from Family Farming (AF). One of the attributions of PNAE nutritionists is to participate in the food purchase process. This article aims to investigate how nutritionists work to facilitate acquisitions from AF in cities from Rio Grande do Sul (RS) with difficulties in complying with the legislation. This is a descriptive study with quantitative approach. Secondary data was collected from a questionnaire answered by nutritionists from 28 municipalities in RS in 2018. The results showed that $82,1 \%$ of municipalities have an inadequate technical board of nutritionists; $78,6 \%$ of nutritionists have access to the local agricultural map when planning the menus; $85,7 \%$ of nutritionists monitor the purchase process from AF; $71,4 \%$ of municipalities promote articulation meetings with family farmers. More detailed studies are needed in order to evaluate engagement and quality of activities carried out by nutritionists in the AF purchasing process for the PNAE.

Keywords: Nutritionists, family farming; School feeding; Nutrition programs and policies; Food and Nutrition Security.

Submetido em: 09/11/2020

Aceito em: 25/11/2021

\section{INTRODUÇÃO}

Em vigência desde 1955, o Programa Nacional de Alimentação Escolar (PNAE) é uma das maiores políticas de alimentação escolar do mundo e tem apresentado diversos avanços em sua operacionalização. Ao longo dos anos, passou de um programa de caráter assistencialista de suplementação alimentar com gestão centralizada no Ministério da Educação e alta oferta de alimentos industrializados para um programa de cobertura universal ao ensino básico da rede pública, com gestão descentralizada nos municípios, estados e Distrito Federal e com refeições elaboradas predominantemente a partir de alimentos in natura $\mathrm{e}$ minimamente processados $[1,2,3,4,5]$.

O PNAE é coordenado pelo Fundo Nacional de Desenvolvimento da Educação (FNDE), que faz repasses financeiros às Entidades Executoras (EEx) - secretarias estaduais de educação, prefeituras e escolas federais - para a compra de gêneros alimentícios ${ }^{[1,3]}$. Segundo dados do FNDE[6], em 2017, o PNAE atendeu mais de 40,9 milhões de alunos com um investimento de mais de 3,89 bilhões de reais. $\mathrm{O}$ valor destinado por estudante segue o disposto no art. 47 da Resolução no 06/2020, que deve ser complementado por contrapartida das EEx para atender às demandas locais ${ }^{[4]}$.

O Programa objetiva contribuir para o crescimento, o desenvolvimento biopsicossocial, a aprendizagem, o rendimento escolar e a formação de práticas alimentares saudáveis dos alunos por meio de ações de educação alimentar e nutricional e da oferta de refeições que cubram suas necessidades nutricionais no período letivo[7]. Enquanto estratégia promotora da Segurança Alimentar e Nutricional (SAN) no país, o PNAE se tornou internacionalmente reconhecido também pela sua interface com a sustentabilidade ${ }^{[8,3]}$. Inclusive, $\mathrm{O}$ Brasil participa de acordos internacionais com a Organização das Nações Unidas para Alimentação e a Agricultura (FAO) e com o Programa Mundial de Alimentos (PMA) para cooperar com o desenvolvimento de Programas de Alimentação Escolar Sustentáveis em países da América Latina, Caribe, África e Ásia[3]. 
$\mathrm{Na}$ primeira década dos anos 2000, o fortalecimento da pauta da SAN como prioridade de governo resultou na criação do Sistema Nacional de Segurança Alimentar e Nutricional (SISAN), em 2006, e da Política Nacional de Segurança Alimentar e Nutricional (PNSAN), em 2010, orientadas por uma nova definição de $\mathrm{SAN}$, mais abrangente do que as interpretações ainda mobilizadas internacionalmente, que enfatizam questões de produtividade e de qualidade higiênico-sanitária e nutricional dos alimentos ${ }^{[9,10,11]}$. Elaborada com a participação da sociedade civil, a concepção brasileira de SAN passou a incorporar o Direito Humano à Alimentação Adequada (DHAA) e a sustentabilidade em suas dimensões ambiental, cultural, econômica e social, conforme disposto na Lei no 11.346 de 2006 [10].

A segurança alimentar e nutricional consiste na realização do direito de todos ao acesso regular e permanente a alimentos de qualidade, em quantidade suficiente, sem comprometer o acesso a outras necessidades essenciais, tendo como base práticas alimentares promotoras de saúde que respeitem a diversidade cultural e que sejam ambiental, cultural, econômica e socialmente sustentáveis.

Assim, as ações de SAN no Brasil buscaram se alinhar a tais preceitos. No caso do PNAE, a partir de 2009, a Lei no 11.947[7] estabeleceu a obrigatoriedade da aplicação de, no mínimo, 30\% dos recursos do FNDE na aquisição de alimentos oriundos da Agricultura Familiar (AF). Esta normativa é considerada um marco histórico na política de alimentação escolar do Brasil, pois uniu a promoção da sustentabilidade socioambiental à estratégia de acesso e distribuição de alimentos ${ }^{[8]}$. Essa condição é fundamentada nas diretrizes do Programa, que preconizam o desenvolvimento sustentável e o incentivo à aquisição de gêneros alimentícios diversificados produzidos em âmbito local pela AF e pelos empreendedores familiares rurais [7]. Além disso, o PNAE também prioriza a escolha por alimentos orgânicos e/ou agroecológicos e da sociobiodiversidade local, considerando a sazonalidade e a cultura alimentar local[12,4].

Desta forma, a conexão entre a alimentação escolar e a AF local pode criar oportunidade para a geração de renda para agricultores familiares, para evitar o êxodo rural, para dinamizar as economias locais, para promover sistemas agroalimentares sustentáveis e para fortalecer o nexus entre nutrição, agricultura e proteção social. Para os alunos beneficiados pelo Programa, pode ser uma oportunidade de acessar refeições elaboradas com alimentos de melhor qualidade, mais frescos, nutritivos e diversificados, contribuindo para a formação de hábitos alimentares saudáveis, especialmente quando associado às atividades de educação alimentar e nutricional[13,8,14].

Ao analisar a evolução das compras públicas da AF no PNAE entre 2011 e 2017, observa-se uma tendência de aumento contínuo no número de EEx que fazem aquisições dessa natureza, no entanto, ainda existe uma grande parcela de municípios que não alcança o mínimo de compras da AF previsto na legislação ${ }^{[15]}$. $O$ não atingimento da meta costuma estar relacionado à existência de dificuldades para lidar com as realidades das estruturas locais, conforme já relatado na literatura, por exemplo: inviabilidade do fornecimento regular de gêneros alimentícios pelos agricultores; falta de articulação entre os atores do PNAE e os fornecedores para o planejamento dos cardápios e da produção dos alimentos; dificuldades na organização da produção, comercialização e logística pelos agricultores ${ }^{[2,14]}$. A fim de estimular o cumprimento da legislação, o FNDE determinou que, a partir de 2021, as EEx que não investirem $30 \%$ dos recursos na $\mathrm{AF}$ deverão devolver o valor referente ao percentual não executado, salvo em algumas situações justificáveis descritas no art.29 da Resolução no 06/2020[4].

Conforme dados de 2017 do FNDE, 37,2\% dos municípios do Brasil usaram menos de 30\% dos recursos do FNDE para aquisições da AF e 14,2\% não adquiriram nenhum produto da AF. Entre as regiões do país, o Sul apresentou o maior percentual de conformidade com a legislação $(82,1 \%)$. No Rio Grande do Sul, no mesmo período, $82,3 \%$ dos municípios atingiram a meta da Lei, enquanto 16,1\% dos municípios compraram da AF usando menos de $30 \%$ dos recursos do FNDE e somente 1,6\% dos municípios não adquiriram produtos da $\mathrm{AF}^{[15]}$.

Outra importante conquista na trajetória do PNAE se deu em 2006, quando passou a ser exigida a presença de nutricionista como Responsável Técnico pelo Programa e de quadro técnico formado por esses profissionais nas EEx, o que tem refletido em melhorias na qualidade do PNAE[3]. No que se 
refere à participação do nutricionista no processo de compras da AF para a alimentação escolar, destacamse alguns pontos referidos na Resolução do Conselho Federal de Nutricionistas (CFN) no 465/2010[16], que dispõe sobre as atribuições deste profissional no âmbito do PNAE: é de responsabilidade do nutricionista planejar, elaborar, acompanhar e avaliar o cardápio da alimentação escolar respeitando os hábitos alimentares e a cultura alimentar local, a sua vocação agrícola e a alimentação saudável e adequada; interagir com os agricultores familiares e empreendedores familiares rurais e suas organizações para conhecer a produção local e incluir esses produtos nos cardápios, priorizando alimentos orgânicos e/ou agroecológicos; participar do processo de licitação e da compra direta da agricultura familiar, colaborando na parte técnica (especificações, quantitativos, entre outros).

$\mathrm{Na}$ literatura, encontram-se artigos que refletem sobre a atuação dos nutricionistas no PNAE, especialmente avaliando a existência de nutricionista responsável técnico nas EEx, a adequação do número destes profissionais conforme parâmetros da Resolução do CFN no 465/2010[16], e a execução das suas diversas atribuições ${ }^{[17,18,19,20,21,22]}$. Porém, não há artigos que investiguem mais detalhadamente o envolvimento desses profissionais no processo de compras da AF. Considerando-se o papel fundamental do nutricionista na aquisição de alimentos da $\mathrm{AF}$ e a falta de pesquisas com esse enfoque, este estudo teve o objetivo de investigar a atuação desse profissional na viabilização da compra da AF em municípios gaúchos que apresentam dificuldade em atingir o percentual mínimo de investimento em aquisições dessa natureza previsto na legislação.

\section{METODOLOGIA}

Este é um estudo quantitativo descritivo com utilização de dados secundários obtidos de questionários elaborados pelo Centro Colaborador em Alimentação e Nutrição do Escolar (CECANE) da Universidade Federal do Rio Grande do Sul (UFRGS) e enviados às nutricionistas de municípios do Rio Grande do Sul (RS) selecionados para a realização de "Oficinas regionais para o levantamento da demanda da alimentação escolar e da produção da agricultura familiar para a boa execução do PNAE". O objetivo destas oficinas foi incentivar os municípios gaúchos, que usam menos de 30\% dos recursos do FNDE para a compra da AF, a atingirem a meta estabelecida pela legislação. As oficinas foram uma demanda do FNDE e este estabeleceu que seriam contemplados 28 municípios que investissem entre $15 \%$ e $29 \%$ de recursos do FNDE em produtos da AF. A partir dessa faixa percentual, o CECANE UFRGS elaborou critérios de seleção considerando a aquisição em diferentes sequências de anos: 1) em 2014, 2015 e 2016 (três anos seguidos); 2) em 2016 e 2015 ou 2016 e 2014 (dois anos); 3) em 2016; 4) em 2015 ou 2014. Também foi considerada a proximidade entre os municípios para que fossem formados grupos regionais. Destaca-se ainda que, após o mapeamento dos municípios com os referidos critérios, houve a necessidade de flexibilizar o critério de seleção segundo a compra entre 15 e $29 \%$, de modo que foram selecionados alguns municípios abaixo do percentual de $15 \%$ para atingir o número mínimo de 28 municípios. Desta forma, foram identificados municípios localizados em quatro regiões: Região Sul (7 municípios); Região Médio Alto Uruguai (6 municípios); Região Alto da Serra (7 municípios) e Região das Missões (8 municípios).

Para a realização da ação "Oficinas regionais para o levantamento da demanda da alimentação escolar e da produção da agricultura familiar para a boa execução do PNAE" nos municípios, foram elaborados três questionários estruturados com perguntas fechadas e abertas: um direcionado às governanças (Secretário/a da Educação), um voltado aos técnicos das Empresas de Assistência Técnica e Extensão Rural (EMATER) e outro para a nutricionista responsável técnica da alimentação escolar de cada município. A sistematização das ferramentas foi determinada em vista da importância desses atores para o bom andamento das compras da $\mathrm{AF}$, buscando-se identificar problemas/dificuldades na atuação dos referidos profissionais. Os questionários foram elaborados em formulário eletrônico no Google Forms e os links para acesso e preenchimento foram enviados por correio eletrônico para os responsáveis de cada setor nos municípios previamente às oficinas. $\mathrm{O}$ presente trabalho focou no questionário respondido pelas nutricionistas responsáveis técnicas dos municípios, sendo que de um total de 53 perguntas, foram selecionadas para análise 24 questões diretamente relacionadas com a atuação desse profissional, 
apresentadas no Quadro 1, agrupadas por área temática. O questionário é composto predominantemente por perguntas fechadas (dicotômicas e de múltipla escolha). As questões 3, 8, 14, 16 e 20 são abertas, visando especificar as respostas das perguntas fechadas que as antecedem, e foram analisadas de acordo com Henkel[23]. A coleta e análise dos dados foram realizadas entre maio e novembro de 2018.

Quadro 1. Questões selecionadas para análise, extraídas do questionário elaboradopela equipe do CECANE UFRGS, em 2018, às nutricionistas dos municípios do Rio Grande do Sul selecionados para o projeto de assessoria "Oficinas regionais para o levantamento da demanda da alimentação escolar e da produção da agricultura familiar para a boa execução do PNAE”, agrupadas por área temática.

\author{
Adequação do quadro técnico de nutricionistas \\ 1. A EEx possui nutricionista habilitado que assume a responsabilidade técnica do Programa? \\ 2. A EEx possui outros nutricionistas lotados no setor de alimentação escolar, compondo o Quadro Técnico (QT)? \\ 3. Se sim, quantos?

\section{Elaboração de cardápios} \\ 4. Existe elaboração de cardápio para a alimentação escolar? \\ 5. O nutricionista da EEx possui conhecimento sobre a cultura alimentar local (hábitos alimentares locais)? \\ 6. Se sim, os cardápios são elaborados de acordo com a cultura alimentar (hábitos alimentares locais)? \\ 7. São inseridos no cardápio alimentos regionais? \\ 8. Se sim, quais? \\ 9. Com qual frequência estes alimentos regionais estão presentes no cardápio? \\ 10. No processo de elaboração dos cardápios, o nutricionista teve acesso ao mapeamento agrícola local? \\ 11. Os produtos disponíveis no município e/ou região são contemplados no processo de compras da Agricultura Familiar (estão na \\ pauta de compras)? \\ 12. O nutricionista acompanha o processo de compras dos produtos da agricultura familiar (Edital de Chamada Pública ou licitação)? \\ 13. Como é a aceitação dos alunos em relação aos alimentos oriundos da Agricultura Familiar? \\ 14. Caso a aceitação seja regular ou ruim, qual seria o motivo? \\ 15. Como é a aceitação dos produtos da agricultura familiar pelos manipuladores de alimentos? \\ 16. Caso a aceitação seja regular ou ruim, qual seria o motivo?
}

\title{
Articulação com outros atores do PNAE
}

17. Ocorrem no município reuniões de articulação entre a EEx com os agricultores familiares locais para tratar sobre a compra destes gêneros?

18. Se sim, o nutricionista participa destas reuniões?

19. Qual é a frequência destas reuniões de articulação entre os envolvidos com a compra da agricultura familiar?

20. Que assuntos são discutidos nestas reuniões?

\section{Opinião sobre a agricultura familiar}

21. Em sua opinião, qual a importância da Agricultura Familiar no desenvolvimento do seu município?

22. Em sua opinião, qual é a importância da compra da Agricultura Familiar para a alimentação escolar?

23. Em sua opinião, qual o grau de interesse dos agricultores do seu município em vender para a alimentação escolar?

24. Em sua opinião, qual o percentual de compra de gêneros para a alimentação escolar, oriundos da agricultura familiar, que seu município deveria e/ou teria potencial de atingir?

Fonte: Elaborado pelos autores

Os dados obtidos, tanto nas questões fechadas quanto abertas, foram armazenados em bancos de dados criados pela equipe do CECANE UFRGS em planilhas Microsoft Office Excel @ 2007 e analisados de forma quantitativa. As questões selecionadas são apresentadas como variáveis, organizadas em quatro tabelas temáticas: 1) adequação do quadro técnico (QT) de nutricionistas por município; 2) elaboração dos cardápios; 3) articulação com outros atores do PNAE; 4) opinião sobre a AF. As opções de respostas das questões fechadas são apresentadas nas tabelas junto à coluna 
O nutricionista e as compras da agricultura familiar no PNAE. Gallicchio et al.

das variáveis (o elemento central da pergunta aparece em negrito, e, logo abaixo, seguem as opções de resposta), com exceção da Tabela 1 , em que as respostas sobre os quantitativos de nutricionistas por município foram organizadas junto à respectiva população de alunos atendida, a fim de analisar a adequação do número de nutricionistas nos municípios. Para tanto, seguimos os parâmetros estabelecidos pela Resolução do Conselho Federal de Nutricionistas (CFN) no 465 de 23 de agosto de 2010 [16] e utilizamos dados do número de alunos do Censo Escolar referente ao ano de 2018 disponibilizados para consulta no website do FNDE[24].

As respostas das questões abertas não foram incluídas nas tabelas (com exceção da questão 3, que consta na Tabela 1), tendo em vista a grande variedade de retornos recebidos e o espaço limitado das tabelas. Portanto, optou-se pela apresentação destas respostas diretamente no texto junto às discussões. Os resultados das questões fechadas e abertas são apresentados em frequências absolutas e relativas das variáveis coletadas, sendo que, nas tabelas, esses valores são organizados por região do Rio Grande do Sul e, nas tabelas 2, 3 e 4, também foi quantificado o valor total das regiões analisadas.

\section{Considerações Éticas}

Os dados utilizados neste trabalho são oriundos de um projeto de extensão da Universidade Federal do Rio Grande do Sul, intitulado: "Centro Colaborador em Alimentação e Nutrição do Escolar 2018", cadastrado sob o no 36973, realizado em parceria com o Fundo Nacional para o Desenvolvimento da Educação do Ministério da Educação. Esta pesquisa utilizou dados de um produto demandado pelo FNDE, e, sendo assim, a utilização desses dados foi também autorizada por este órgão.

\section{RESULTADOS E DISCUSSÕES}

A Tabela 1 apresenta dados referentes à adequação do número de nutricionistas em cada município, calculada conforme os parâmetros da Resolução CFN no 465/2010[16] que consideram a proporcionalidade entre o número de nutricionistas e número de alunos atendidos (da educação básica e infantil). É importante mencionar que, além da proporção numérica nutricionistas/alunos, a Resolução CFN no 465/2010 também considera a carga horária técnica que seria adequada para as nutricionistas cumprirem suas atribuições, sendo recomendado, no mínimo, $30 \mathrm{~h} / \mathrm{semana}$. No entanto, a variável carga horária não foi avaliada na Tabela 1 devido à falta dessa informação sobre os municípios. 
Tabela 1. Adequação do número de Nutricionistas dos municípios selecionados para o estudo no Rio Grande do Sul, por região, conforme os parâmetros da Resolução do Conselho Federal de Nutricionistas (CFN) no 465, de 23 de agosto de 2010. Dados de 2018.

\begin{tabular}{|c|c|c|c|c|}
\hline \multirow[t]{2}{*}{ Municípios por Região } & \multicolumn{2}{|c|}{ № de alunos } & \multirow{2}{*}{$\begin{array}{l}\text { RT e QT do } \\
\text { Municípioº }^{2}\end{array}$} & \multirow{2}{*}{$\begin{array}{c}\text { Adequação ao } \\
\text { Parâmetro RT e } \\
\text { QT do CFN³ }\end{array}$} \\
\hline & $\begin{array}{c}\text { Educação } \\
\text { Básica } \\
(\text { EB })^{1} \\
\end{array}$ & $\begin{array}{c}\text { Educação } \\
\text { Infantil } \\
(\mathrm{EI})^{1} \\
\end{array}$ & & \\
\hline Região das Missões & & & & \\
\hline Município 1 & 235 & 158 & $1 \mathrm{RT}$ & Inadequado \\
\hline Município 2 & 52 & 42 & $1 \mathrm{RT}$ & Inadequado \\
\hline Município 3 & 99 & 49 & $1 \mathrm{RT}$ & Inadequado \\
\hline Município 4 & 561 & 394 & $1 \mathrm{RT}$ & Inadequado \\
\hline Município 5 & 406 & 150 & $1 \mathrm{RT}$ & Inadequado \\
\hline Município 6 & 236 & 74 & $1 \mathrm{RT}$ & Inadequado \\
\hline Município 7 & 97 & 84 & $1 \mathrm{RT}+1 \mathrm{QT}$ & Adequado \\
\hline Município 8 & 1006 & 617 & $1 \mathrm{RT}$ & Inadequado \\
\hline \multicolumn{5}{|l|}{ Região Sul } \\
\hline Município 9 & 1039 & 577 & $1 \mathrm{RT}$ & Inadequado \\
\hline Município 10 & 583 & 233 & $1 \mathrm{RT}$ & Inadequado \\
\hline Município 11 & 585 & 231 & $1 \mathrm{RT}$ & Inadequado \\
\hline Município 12 & 439 & 188 & $1 \mathrm{RT}$ & Inadequado \\
\hline Município 13 & 663 & 233 & $1 \mathrm{RT}$ & Inadequado \\
\hline Município 14 & 2846 & 1125 & $1 \mathrm{RT}$ & Inadequado \\
\hline Município 15 & 9558 & 3768 & $1 \mathrm{RT}+2 \mathrm{QT}$ & Inadequado \\
\hline \multicolumn{5}{|c|}{ Região Médio Alto Uruguai } \\
\hline Município 16 & 184 & 123 & $1 \mathrm{RT}+1 \mathrm{QT}$ & Adequado \\
\hline Município 17 & 145 & 79 & $1 \mathrm{RT}$ & Inadequado \\
\hline Município 18 & 149 & 109 & $1 \mathrm{RT}$ & Inadequado \\
\hline Município 19 & 197 & 76 & $1 \mathrm{RT}$ & Inadequado \\
\hline Município 20 & 220 & 137 & $1 \mathrm{RT}$ & Inadequado \\
\hline Município 21 & 163 & 108 & $1 \mathrm{RT}+1 \mathrm{QT}$ & Adequado \\
\hline \multicolumn{5}{|l|}{ Região Alto da Serra } \\
\hline Município 22 & 868 & 285 & $1 \mathrm{RT}$ & Inadequado \\
\hline Município 23 & 221 & 89 & $1 \mathrm{RT}$ & Inadequado \\
\hline Município 24 & 501 & 302 & $1 \mathrm{RT}$ & Inadequado \\
\hline Município 25 & 244 & 147 & $1 \mathrm{RT}+1 \mathrm{QT}$ & Adequado \\
\hline Município 26 & 77 & 74 & $1 \mathrm{RT}+1 \mathrm{QT}$ & Adequado \\
\hline Município 27 & 912 & 335 & $1 \mathrm{RT}+1 \mathrm{QT}$ & Inadequado \\
\hline Município 28 & 311 & 259 & $1 \mathrm{RT}$ & Inadequado \\
\hline
\end{tabular}

Observa-se que somente cinco $(17,9 \%)$ dos 28 municípios analisados possuem QT adequado à quantidade de alunos que atendem. Apenas um município (12,5\%) na Região das Missões mostrouse adequado, dois $(33,3 \%)$ na Região Médio Alto Uruguai e dois $(28,6 \%)$ na Região Alto da Serra. Cabe destacar que na Região Sul nenhum dos municípios apresentou QT adequado. Em relação aos cinco municípios classificados como adequados em QT, deve-se destacar que a adequação da carga horária das profissionais não foi avaliada. Todos os municípios possuem nutricionista responsável técnico (RT), sendo que em 21 (75\%) municípios, este nutricionista atua sozinho, sem QT de apoio. Segundo a Resolução CFN no 465/2010[16], sempre que houver alunos de ensino infantil (EI) deve haver um nutricionista 
específico para esse público. Apesar de o questionário não ter abordado essa questão, o fato de $75 \%$ das localidades terem somente um profissional para todos os alunos indica que a maioria dos municípios não tem nutricionista específico para o EI.

Esses resultados vão ao encontro do estudo de Corrêa et al. [18], que identificou que 71,6\% dos municípios da Região Sul do Brasil possuem QT inadequado e 97,4\% não possuem nutricionista específico para a EI. Ao avaliarem a atuação dos nutricionistas na região, os autores verificaram que duas das treze atribuições obrigatórias do nutricionista no PNAE[16] (elaboração de fichas técnicas dos cardápios e elaboração de Manual de Boas Práticas) eram realizadas por menos da metade dos municípios. Contudo, embora as demais atividades sejam realizadas pela maioria dos municípios, faltam dados sobre sua qualidade, frequência e grau de complexidade.

Alguns estudos apontam que os nutricionistas do PNAE enfrentam dificuldades para cumprir todas as suas atividades técnicas devido à sobrecarga de atividades burocráticas e administrativas ${ }^{[17,21,22]}$. Chaves et al.[17] atentam para a evolução das atribuições dos nutricionistas do PNAE: se inicialmente eram responsáveis somente pela elaboração dos cardápios, com o tempo foram sendo incorporadas uma série de outras atividades técnicas ${ }^{[7,16]}$ que aumentaram a complexidade de seu trabalho. Vale lembrar que com a recente atualização das Resoluções no 26/2013 e no 04/2015 para as Resoluções no 06/2020 e no 20/2020, que dispõem sobre o atendimento da alimentação escolar aos alunos da educação básica no âmbito do PNAE, os nutricionistas estão se deparando com novas exigências, especialmente quanto à qualidade dos cardápios, que demandam tempo para estudo e aplicação na prática. Da mesma forma, frente ao atual contexto de pandemia ocasionada pela COVID-19 a partir de 2020, os nutricionistas estão encarando o desafio de adaptar a logística da alimentação escolar a fim de garantir o direito à alimentação adequada tanto dos alunos com aulas presenciais quanto daqueles em ensino remoto (ou híbrido), mediante refeições nas escolas e entregas de kits de alimentos às famílias, sempre seguindo os devidos protocolos de segurança ${ }^{[25,26,27]}$. Chaves et al.[17], ao refletirem sobre a sobrecarga de responsabilidades das nutricionistas do PNAE, apontam a possibilidade destes buscarem apoio de outros profissionais envolvidos com o Programa, como professores, estagiários, técnicos administrativos, membros dos Conselhos de Alimentação Escolar (CAE), para auxiliarem no cumprimento das atribuições mediante atividades de matriciamento.

Assim, um QT inadequado pode ser um fator de influência no nível de engajamento dos nutricionistas no processo de compras da AF. Machado et al.[28], ao analisarem a compra de alimentos da AF pelo PNAE no universo de municípios brasileiros, observaram que os municípios que contam com a presença de nutricionista RT apresentaram percentuais de compra da AF maiores do que municípios sem esse profissional, demonstrando que o nutricionista é um agente importante nesse processo. No mesmo sentido, o estudo de Ferreira et al.[21], que contemplou dados de 38 municípios do Rio de Janeiro, encontrou associação estatisticamente significativa entre adequação numérica de nutricionistas e compras da agricultura familiar, bem como com a realização de atividades de educação alimentar e nutricional, indicando que a insuficiência de nutricionistas é associada ao baixo percentual de compras da AF.

Apesar do déficit de nutricionistas na alimentação escolar, ressalta-se que, no Brasil, a região Sul apresenta o maior percentual de municípios em conformidade com o Artigo 14 da Lei no $11.947 / 2009$, uma vez que $82,1 \%$ dos municípios utilizaram ao menos $30 \%$ dos recursos do FNDE para compra de gêneros alimentícios da agricultura familiar em 2017[15]. Isso pode indicar que o êxito nas compras depende também de outros fatores, conforme observado por diversos autores: a) do quanto os nutricionistas e demais atores envolvidos com as compras da AF tem conhecimento sobre o processo e se dedicam ao assunto; b) da presença de articulação entre os atores do PNAE (nutricionistas, gestores, agricultores e suas organizações, EMATER e Secretaria da Agricultura); c) das características da produção agrícola local (variedade de alimentos; número de agricultores; escala da produção); d) da formalização das agroindústrias familiares, pois a legislação sanitária atual, voltada para grandes indústrias de produção em larga escala, não condiz com a realidade da produção familiar/artesanal e dificulta sua formalização (exigida para venda aos 
mercados institucionais), o que demanda dos municípios criar mecanismos legais adequados à regularização das pequenas agroindústrias (como um Sistema de Inspeção Municipal - SIM); e) das dificuldades na organização da produção e logística, por parte dos agricultores, para garantir o fornecimento regular e constante de alimentos; f) da adequada redação e divulgação das chamadas

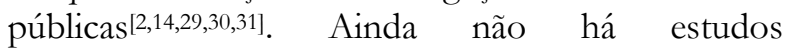
comparando a atuação de nutricionistas de municípios que não atingem os 30\% de compras da AF e de nutricionistas de municípios que atingem tal percentual. Um estudo desse tipo, utilizando-se de análise estatística, seria pertinente para identificar quais são os principais condicionantes e estratégias adotadas para cumprir a lei, apesar da inadequação dos quadros técnicos.

A Tabela 2 contém informações relacionadas ao processo de elaboração de cardápios. 
Tabela 2. Elaboração dos cardápios nos municípios selecionados, em números absolutos e percentuais, organizados por região do Rio Grande do Sul e total das regiões. Dados de 2018.

\begin{tabular}{|c|c|c|c|c|c|c|c|c|c|c|}
\hline \multirow[b]{4}{*}{$\begin{array}{l}\text { Existência de cardápio para a } \\
\text { alimentação escolar }\end{array}$} & \multicolumn{6}{|c|}{ Região } & & \multicolumn{3}{|c|}{ Total } \\
\hline & \multicolumn{2}{|c|}{$\begin{array}{l}\text { Missões } \\
(n=8)\end{array}$} & \multicolumn{2}{|c|}{$\begin{array}{c}\text { Sul } \\
(n=7)\end{array}$} & \multicolumn{2}{|c|}{$\begin{array}{l}\text { Médio Alto } \\
\text { Uruguai } \\
(\mathrm{n}=6)\end{array}$} & \multicolumn{2}{|c|}{$\begin{array}{l}\text { Alto da Serra } \\
\qquad(\mathrm{n}=7)\end{array}$} & \multicolumn{2}{|c|}{$(\mathrm{n}=28)$} \\
\hline & $\mathbf{n}$ & $\%$ & $\mathbf{n}$ & $\%$ & $\mathrm{n}$ & $\%$ & n & $\%$ & n & $\%$ \\
\hline & & & & & & & & & & \\
\hline Sim & 8 & 100 & 7 & 100 & 6 & 100 & 7 & 100 & 28 & 100 \\
\hline \multicolumn{11}{|l|}{$\begin{array}{l}\text { Nutricionista tem conhecimento } \\
\text { sobre a cultura alimentar local }\end{array}$} \\
\hline $\operatorname{Sim}$ & 8 & 100 & 6 & 85,7 & 6 & 100 & 7 & 100 & 27 & 96,4 \\
\hline Não/Parcialmente & 0 & 0 & 1 & 14,3 & 0 & 0 & 0 & 0 & 1 & 3,6 \\
\hline \multicolumn{11}{|l|}{$\begin{array}{l}\text { Se sim, a elaboração dos cardápios } \\
\text { considera a cultura alimentar local }\end{array}$} \\
\hline Sim & 8 & 100 & 6 & 100 & 5 & 83,3 & 6 & 85,7 & 25 & 92,6 \\
\hline Não/Parcialmente & 0 & 0 & 0 & 0 & 1 & 16,7 & 1 & 14,3 & 2 & 7,4 \\
\hline \multicolumn{11}{|l|}{$\begin{array}{l}\text { Os cardápios incluem produtos } \\
\text { regionais }\end{array}$} \\
\hline Sim & 8 & 100 & 7 & 100 & 6 & 100 & 7 & 100 & 28 & 100 \\
\hline Não & 0 & 0 & 0 & 0 & 0 & 0 & 0 & 0 & 0 & 0 \\
\hline
\end{tabular}

\begin{tabular}{|c|c|c|c|c|c|c|c|c|c|c|}
\hline \multicolumn{11}{|l|}{$\begin{array}{l}\text { Se sim, frequência da presença de } \\
\text { produtos regionais }\end{array}$} \\
\hline Diariamente & 0 & 0 & 1 & 14,3 & 0 & 0 & 1 & 14,3 & 2 & 7,1 \\
\hline Semanalmente & 6 & 75 & 4 & 57,1 & 4 & 66,7 & 3 & 42,9 & 17 & 60,7 \\
\hline Mensalmente & 1 & 12,5 & 0 & 0 & 1 & 16,7 & 3 & 42,9 & 5 & 17,9 \\
\hline Não informado & 1 & 12,5 & 2 & 28,6 & 1 & 16,7 & 0 & 0 & 4 & 14,3 \\
\hline \multicolumn{11}{|l|}{$\begin{array}{l}\text { nutricionista teve acesso ao } \\
\text { mapeamento agrícola durante a } \\
\text { elaboração do cardápio }\end{array}$} \\
\hline $\operatorname{Sim}$ & 8 & 100 & 3 & 42,9 & 6 & 100 & 5 & 71,4 & 22 & 78,6 \\
\hline Não & 0 & 0 & 4 & 57,1 & 0 & 0 & 2 & 28,6 & 6 & 21,4 \\
\hline $\begin{array}{lr}\text { Os produtos disponíveis no } & \text { no } \\
\text { município/região } & \text { são } \\
\text { contemplados no processo de } \\
\text { compras da agricultura familiar }\end{array}$ & & & & & & & & & & \\
\hline $\begin{array}{l}\text { Sim, alimentos produzidos no } \\
\text { município }\end{array}$ & 5 & 62,5 & 3 & 42,9 & 2 & 33,3 & 5 & 71,4 & 15 & 53,6 \\
\hline $\begin{array}{l}\text { Sim, alimentos produzidos em } \\
\text { municípios vizinhos }\end{array}$ & 0 & 0 & 0 & 0 & 1 & 16,7 & 1 & 14,3 & 2 & 7,1 \\
\hline $\begin{array}{l}\text { Sim, alimentos produzidos tanto no } \\
\text { município como na região (municípios } \\
\text { vizinhos) }\end{array}$ & 3 & 37,5 & 4 & 57,1 & 3 & 50,0 & 1 & 14,3 & 11 & 39,3 \\
\hline \multicolumn{11}{|l|}{$\begin{array}{l}\text { O nutricionista acompanha o } \\
\text { processo de compras (editais) dos } \\
\text { produtos da agricultura familiar }\end{array}$} \\
\hline $\operatorname{Sim}$ & 8 & 100 & 6 & 85,7 & 5 & 83,3 & 5 & 71,4 & 24 & 85,7 \\
\hline Não/Parcialmente & 0 & 0 & 1 & 14,3 & 1 & 16,7 & 2 & 28,6 & 4 & 14.3 \\
\hline \multicolumn{11}{|l|}{$\begin{array}{l}\text { Aceitação dos alimentos } \mathrm{da} \\
\text { agricultura familiar pelos alunos }\end{array}$} \\
\hline Ótima/boa & 8 & 100 & 7 & 100 & 5 & 83,3 & 7 & 100 & 27 & 96,4 \\
\hline Regular/Baixa & 0 & 0 & 0 & 0 & 1 & 16,7 & 0 & 0 & 1 & 3,6 \\
\hline 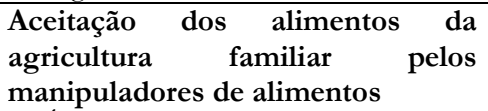 & & & & & & & & & & \\
\hline Ótima/boa & 8 & 100 & 4 & 57,1 & 6 & 100 & 7 & 100 & 25 & 89,3 \\
\hline Regular/Baixa & 0 & 0 & 3 & 42,9 & 0 & 0 & 0 & 0 & 3 & 10,7 \\
\hline
\end{tabular}


Todos os 28 municípios estudados contam com a existência de cardápio elaborado por nutricionista para a alimentação escolar. Quase todas as nutricionistas $27(96,4 \%)$ declararam ter conhecimento sobre a cultura alimentar local e, destas, $25(92,6 \%)$ afirmam considerar a cultura alimentar na elaboração dos cardápios, enquanto duas $(7,4 \%)$ consideram parcialmente. Chaves et al. ${ }^{32]}$, ao analisarem uma amostra de 97 cardápios da Região Sul do país, constataram que $84,2 \%$ deles eram supervisionados por nutricionistas. Pela legislação[7], a elaboração de cardápios é de responsabilidade deste profissional, sendo uma etapa fundamental na viabilização da aquisição de produtos da $\mathrm{AF}$, pois é neste momento que o nutricionista define quais alimentos serão comprados.

Chaves et al.[32] também verificaram que $86,5 \%$ dos cardápios continham de uma a três preparações regionais, sendo oferecidas, em média, 1,7 preparações regionais por semana. Girardi et al.[33] também analisaram cardápios da região sul do Brasil e constataram baixa oferta de preparações regionais, entretanto, ponderam que este resultado pode estar subestimado devido à falta de detalhamento sobre as preparações em alguns cardápios. Assim, as pesquisadoras alertam para a necessidade de melhorar a metodologia de identificação de alimentos regionais em cardápios, indicando $\mathrm{o}$ instrumento desenvolvido por Fabri et al. ${ }^{[34]}$ para futuras avaliações.

No presente estudo, há inclusão de alimentos regionais nos cardápios dos 28 (100\%) municípios, sendo a frequência de uso destes alimentos predominantemente semanal $(\mathrm{n}=17$, $60,7 \%)$, seguido de mensal $(n=5,17,9 \%)$ e diário $(\mathrm{n}=2,7,1 \%)$; quatro municípios não informaram a frequência $(14,3 \%)$. Os gêneros regionais mais mencionados nas compras foram: aipim/mandioca $(n=15,53,6 \%)$; laranja $(n=15,53,6 \%)$; bergamota $(\mathrm{n}=14,50 \%)$; alface, cenoura e beterraba $(\mathrm{n}=10$, $35,7 \%$ cada); batata doce ( $\mathrm{n}=9,32,1 \%)$; feijão ( $\mathrm{n}=9$, $32,1 \%)$; abóbora $(n=8,28,6 \%)$; morango $(n=6$, $21,4 \%)$. No geral, os itens descritos eram majoritariamente hortifrutigranjeiros; 19 (67,9\%) municípios indicaram panificados e massas como cucas, bolachas, pães e massas caseiras; quatro $(14,3 \%)$ municípios referiram leite; cinco $(17,9 \%)$ compram doces artesanais regionais (doce de leite ou de frutas); quatro (14,3\%) descreveram carnes (frango, porco, carne bovina ou salsichão/linguiça) e dois $(7,1 \%)$ indicaram queijos. Somente dois $(7,1 \%)$ municípios citaram pinhão, alimento fortemente ligado ao território gaúcho. Destaca-se que 11 $(39,3 \%)$ nutricionistas informaram que incluem até três variedades de alimentos regionais nos cardápios, indicando que a oferta destes gêneros poderia ser mais diversificada.

A importância da valorização das diferentes expressões de culturas alimentares, alimentos e preparações locais e regionais é destacada no Marco de Referência de Educação Alimentar e Nutricional para as Políticas Públicas ${ }^{[3]}$ e no Guia Alimentar para a População Brasileira ${ }^{[5]}$. Na legislação do PNAE, essa importância é reconhecida ao ser estimulada a compra de alimentos in natura e minimamente processados produzidos a nível local por agricultores e empreendedores familiares rurais, priorizando as comunidades tradicionais indígenas e de remanescentes de quilombos; ao orientar que os cardápios considerem a cultura alimentar local, a sustentabilidade, a sazonalidade e a diversificação agrícola da região; e ao propor que sejam realizadas ações de educação alimentar e nutricional que favoreçam hábitos alimentares regionais e culturais saudáveis e que promovam a utilização de produtos orgânicos e/ou agroecológicos e da sociobiodiversidade[12,4]. A inclusão de alimentos regionais nos cardápios colabora para a manutenção da agrobiodiversidade e das culturas alimentares, para a promoção de dietas diversificadas e nutritivas, para o desenvolvimento econômico sustentável e, consequentemente, para a realização da segurança alimentar e nutricional da população.

Contudo, Fabri et al.[34] refletem que a inclusão de alimentos e preparações regionais na alimentação escolar é um processo complexo por conta da falta de consenso sobre quais alimentos representam a cultura e os hábitos alimentares locais, especialmente considerando que as práticas culturais e os hábitos alimentares podem mudar como resultado de fatores tecnológicos, econômicos e sociais relacionados à produção, acesso e consumo de alimentos. Por vezes, um alimento pode ser equivocadamente classificado como regional por ser produzido na região, mesmo que não tenha relação histórica com esta nem seja habitualmente consumido pela população[33]. De fato, a noção de 
alimento regional ainda não é bem conceituada, havendo várias interpretações. Alguns aspectos que costumam ser considerados para além do local de produção são os hábitos regionais das populações, a associação com valores simbólicos, a referência à identidade local e o contexto histórico do alimento na cidade ${ }^{[34]}$.

Nota-se que as nutricionistas entrevistadas citaram baixa variedade de alimentos nativos da região, demonstrando necessidade de explorar mais a utilização destes produtos na alimentação escolar. A importância do incentivo à produção e consumo desses alimentos se relaciona especialmente à expressiva diminuição, a nível global, do número de espécies de plantas e animais consumidos pela população. Essa perda de diversidade coloca a segurança alimentar global em risco, visto que torna os sistemas agrícolas mais vulneráveis a pragas, patógenos e às mudanças climáticas ${ }^{[36,37]}$. Tal panorama resulta de mudanças no uso da terra, da perda de conhecimentos, das preferências de mercado e do comércio de larga escala, estreitamente ligados aos processos de industrialização, globalização e à Revolução Verde no séc. XX, em que a agricultura se voltou à produção de um restrito grupo de commodities tendo em vista a demanda dos mercados globalizados por uma produção de alimentos intensiva e padronizada[36,37,38,39]. Os impactos negativos desse modelo de produção para o meio ambiente, saúde pública e condições socioeconômicas de populações rurais são amplamente difundidos na literatura ${ }^{[40,41,42,43]}$. A garantia da capacidade adaptativa da produção de alimentos em um contexto de mudanças climáticas e aumento da população implica na adoção de medidas que conservem a diversidade de genes, variedades, cultivares, raças e espécies que também contribuam para a nutrição humana através da alimentação diversificada, saudável e culturalmente relevante[36].

A conservação e o uso dos recursos nativos, bem como da biodiversidade agroalimentar, continuam ligados principalmente às comunidades locais que integraram elementos da paisagem florestal às suas práticas agrícolas e pecuárias, geralmente em produções de pequena escala (no caso do Brasil: agricultores de pequenas propriedades e comunidades tradicionais, como caiçaras, quilombolas e indígenas) [38, 44]. Por conta disso, os alimentos nativos e da sociobiodiversidade não costumam ser encontrados em supermercados, sendo comercializados majoritariamente em redes locais, e, muitas vezes, em sistemas informais de varejo ${ }^{[5]}$. Enquanto um país megabiodiverso, o Brasil utiliza somente uma pequena fração dessa riqueza que ainda é pouco conhecida e subutilizadaa ${ }^{[38,45]}$. Ao privilegiar cultivos exóticos e favorecer a simplificação das dietas, o país deixa de aproveitar o potencial econômico e social da sua biodiversidade ${ }^{[38,45]}$. Por isso, as compras públicas de alimentos são uma excelente oportunidade para estimular a produção, o comércio e o consumo de espécies nativas brasileiras produzidas de forma sustentável. Dessa forma, contribui-se para o fortalecimento da preservação da sociobiodiversidade, entendida como a "inter-relação entre a diversidade biológica e a diversidade de sistemas socioculturais"'[46], e para a diversificação das dietas, especialmente aumentando o acesso a alimentos ricos em micronutrientes, como frutas, legumes e verduras.

A fim de promover os produtos da sociobiodiversidade no Brasil, foi lançado em 2009 o Plano Nacional de Promoção das Cadeias de Produtos da Sociobiodiversidade (PNPSB) ${ }^{[46]}$, pautado por valores socioambientais como conservação e uso sustentável da biodiversidade, inclusão socioprodutiva de comunidades tradicionais e agricultores familiares, valorização da diversidade cultural e do conhecimento tradicional, repartição justa e equitativa de benefícios, cooperação, solidariedade e ética. Um de seus eixos de ação refere-se à estruturação e fortalecimento de mercados para produtos da sobiobiodiversidade, sendo apontada como uma linha de ação a ampliação da participação desses produtos nas compras governamentais. Nota-se que a normativa da inclusão da AF no PNAE se deu no mesmo ano, demonstrando alinhamento com o PNPSB. Contudo, apesar dos avanços legais, estudos têm constatado baixa presença desses alimentos nos cardápios escolares ${ }^{[3,47,48]}$. Além disso, pesquisas sobre esse tema ainda são escassas na literatura, merecendo mais atenção.

No caso do PNAE, o diálogo entre nutricionistas, agricultores/cooperativas de agricultores, EMATER e Secretaria da Agricultura locais e CECANE regional pode ajudar no processo de reconhecimento da sociobiodiversidade local e de 
espécies nativas que poderiam ter sua produção incentivada, e na facilitação de sua conexão com a alimentação escolar. Também existem materiais de apoio à promoção da biodiversidade agrícola com especial atenção para a ampliação do uso de espécies nativas na alimentação que valem a pena serem consultados: a recente publicação do Projeto Biodiversidade para Alimentação e Nutrição (BFN) "Biodiversidade Brasileira: Sabores e Aromas"[45] apresenta 335 receitas elaboradas a partir de 64 espécies nativas da flora brasileira de grande potencial, selecionadas da "Iniciativa Plantas para o Futuro" do Ministério do Meio Ambiente, organizadas por região do país; a Portaria Interministerial MAPA/MMA no 10, de 21 de julho de 2021 "institui lista de espécies nativas da sociobiodiversidade de valor alimentício, para fins de comercialização in natura ou de seus produtos derivados"[49], com exemplos de uso culinário e indicação da distribuição geográfica das espécies no país; e o livro "Plantas Alimentícias Não Convencionais (PANC) no Brasil: Guia de Identificação, Aspectos Nutricionais e Receitas Ilustradas"[50], que apresenta plantas nativas $\mathrm{e}$ exóticas subutilizadas no Brasil.

Em relação ao mapeamento agrícola local, $22(78,6 \%)$ nutricionistas relataram ter acesso a esse levantamento durante a elaboração do cardápio. A EMATER e a Secretaria da Agricultura locais podem ser referências para a busca de informações sobre a produção da $\mathrm{AF}$, além do contato direto com os agricultores, que é uma das atribuições obrigatórias do nutricionista[16]. A aproximação com os agricultores permite que sejam acordadas dinâmicas para melhor atender as demandas da alimentação escolar. Tendo em vista que a consulta ao mapeamento agrícola local/regional é uma etapa essencial para a elaboração dos cardápios com produtos da AF, a falta desse acesso pode contribuir para um baixo percentual de compras da AF. Observa-se, contudo, que a maioria das nutricionistas acessa o mapeamento, o que pode indicar a existência de outras dificuldades no processo de compra, como problemas na elaboração e divulgação das chamadas públicas, falta de formalização dos agricultores, dificuldades destes em suprir as demandas, entre outros motivos que não foram analisados neste estudo. Sabe-se que o mapeamento informa somente a produção local, portanto o diálogo entre a nutricionista e os agricultores e/ou suas entidades representativas é essencial para elaborar uma chamada pública condizente com as possibilidades de oferta. Mais adiante no artigo é analisada a ocorrência de reuniões de articulação nos municípios, mas destacamos aqui que, das 22 nutricionistas que acessam o mapeamento, 6 relataram que seu município não realiza reuniões, e uma nutricionista afirmou que apesar do seu município realizar reunião, ela não participa.

Em relação à inclusão de produtos disponíveis no município/região no processo de compras da AF, 15 (53,6\%) municípios contemplam somente alimentos produzidos no próprio município, enquanto dois $(7,1 \%)$ municípios incluem alimentos somente de municípios vizinhos e 11 (39,3\%) municípios abrangem alimentos produzidos tanto localmente quanto na região. A legislação do PNAE orienta que seja dada preferência aos fornecedores locais, seguido por fornecedores da região, do Estado e, por fim, do território nacional[12,4]. Assim, é positivo que a maioria dos municípios esteja adquirindo alimentos locais. Por outro lado, o percentual de casos que não consideram a produção regional merece atenção, visto que não estão aproveitando o potencial desta via para aumentar as compras da AF, o que poderia contribuir para atingir a meta da legislação. Estes municípios poderiam buscar conexões com outros gestores e formar redes regionais para compartilhar ofertas/mapeamentos agrícolas de seus municípios com vizinhos, bem como contatar cooperativas e associações regionais e incentivar a formação destas, dado o maior número de produtores beneficiados e a possibilidade de venda de alimentos em maior escala nessa conformação. Os nutricionistas podem e devem auxiliar nessas articulações, respaldadas pela legislação brasileira ${ }^{[16]}$.

Bezerra et al.[51] relataram uma intervenção de articulação de redes intersetoriais presenciais em Territórios da Cidadania, conduzidos por equipes formadas por nutricionista, educador popular e engenheiro agrônomo ou técnico agrícola, com o objetivo de mobilizar atores locais para a promoção da compra de produtos da AF para a alimentação escolar. Após a ação, $14 \%$ dos municípios melhoraram a organização da $\mathrm{AF}$, aumentando as aquisições desta. É uma demonstração de que a organização social em associações e cooperativas favorece o acesso aos editais de chamada pública[52] 
e, por conseguinte, a prática da Lei no 11.947/2009. Percebe-se que as mudanças de realidade não são dependentes somente dos representantes políticos, mas também da iniciativa da sociedade em participar de forma efetiva das questões públicas.

Os nutricionistas de 24 (85,7\%) municípios referiram acompanhar o processo de compras (editais) da AF, enquanto quatro $(14,3 \%)$ nutricionistas o fazem de forma parcial ou não acompanham. No entanto, essa questão não especifica o grau de envolvimento. Corrêa et al. ${ }^{[18]}$, ao avaliarem a participação de nutricionistas no processo de compra da AF em municípios da Região Sul do Brasil, constataram que $86 \%$ dos profissionais participavam do planejamento da entrega, 83,9\% trabalhavam no levantamento da demanda de gêneros, $83,0 \%$ supervisionavam o recebimento e armazenamento dos produtos, $86,8 \%$ ajudavam a elaborar a pauta de compras, $73,2 \%$ auxiliavam no diagnóstico da produção local, 52,7\% faziam avaliação técnica das amostras e 52,7\% avaliavam os fornecedores. Seria importante aprofundar esse conhecimento em municípios com dificuldade de compra da AF para o PNAE.

Quanto à aceitação dos alimentos da AF pelos alunos, $27(96,4 \%)$ nutricionistas consideram ótima/boa, assim como a aceitação por parte dos manipuladores $(\mathrm{n}=25,89,3 \%)$. Não conseguimos identificar o motivo da única classificação da aceitação dos alunos como regular, porque não recebemos uma resposta compreensiva para a questão 14. Já as justificativas descritas para as aceitações inferiores entre os manipuladores foram: dificuldade na higienização dos hortifrutigranjeiros $(\mathrm{n}=1,3,6 \%)$ e a falta de hábito de consumo desses alimentos $(n=1,3,6 \%)$, que acaba dificultando o preparo, e uma nutricionista não especificou sua resposta. Ambos os casos podem ser contornados verificando se a cultura e hábitos alimentares locais estão sendo considerados na elaboração dos cardápios e na aquisição dos gêneros alimentícios e, caso sim, dialogar com os manipuladores de alimentos sobre educação alimentar e nutricional e realizar treinamentos para se familiarizarem com os produtos, formas de preparo e adequada higienização. Não foram encontrados relatos de aplicação de testes de aceitabilidade para alimentos ou preparações com alimentos da AF no PNAE na literatura, mas há trabalhos ${ }^{[14,53]}$ que apresentam opiniões de manipuladoras entrevistadas. Destas, a maioria considera a qualidade dos alimentos entre ótima/boa e referem boa aceitação pelos estudantes, além de os cardápios estarem mais variados e com presença de alimentos mais frescos. Como pontos negativos, mencionaram a necessidade de realizar adaptações no cardápio em decorrência de falhas nas entregas da AF, e também mudanças nas rotinas de trabalho, visto que a maior presença de vegetais demanda mais tempo de pré-preparo e consideram que estes alimentos chegam à escola com mais sujidades, demorando mais para higienizá-los. Apesar disso, as manipuladoras reforçam os benefícios dessas aquisições na qualidade dos cardápios. Alexandre et al. ${ }^{54]}$ citaram a inadequação da infraestrutura das Unidades de Alimentação e Nutrição (UAN) de escolas para armazenar, preparar ou servir alimentos da AF como um impedimento para a compra destes em alguns municípios. Nesse caso, compete ao nutricionista fazer supervisão das UAN e cobrar as adequações dos gestores municipais.

$\mathrm{Na}$ Tabela 3 são abordadas questões sobre articulação entre os atores do PNAE. 
Tabela 3. Articulação dos nutricionistas com outros atores do PNAE nos municípios selecionados, em números absolutos e percentuais, organizados por região do Rio Grande do Sul e total das regiões. Dados de 2018.

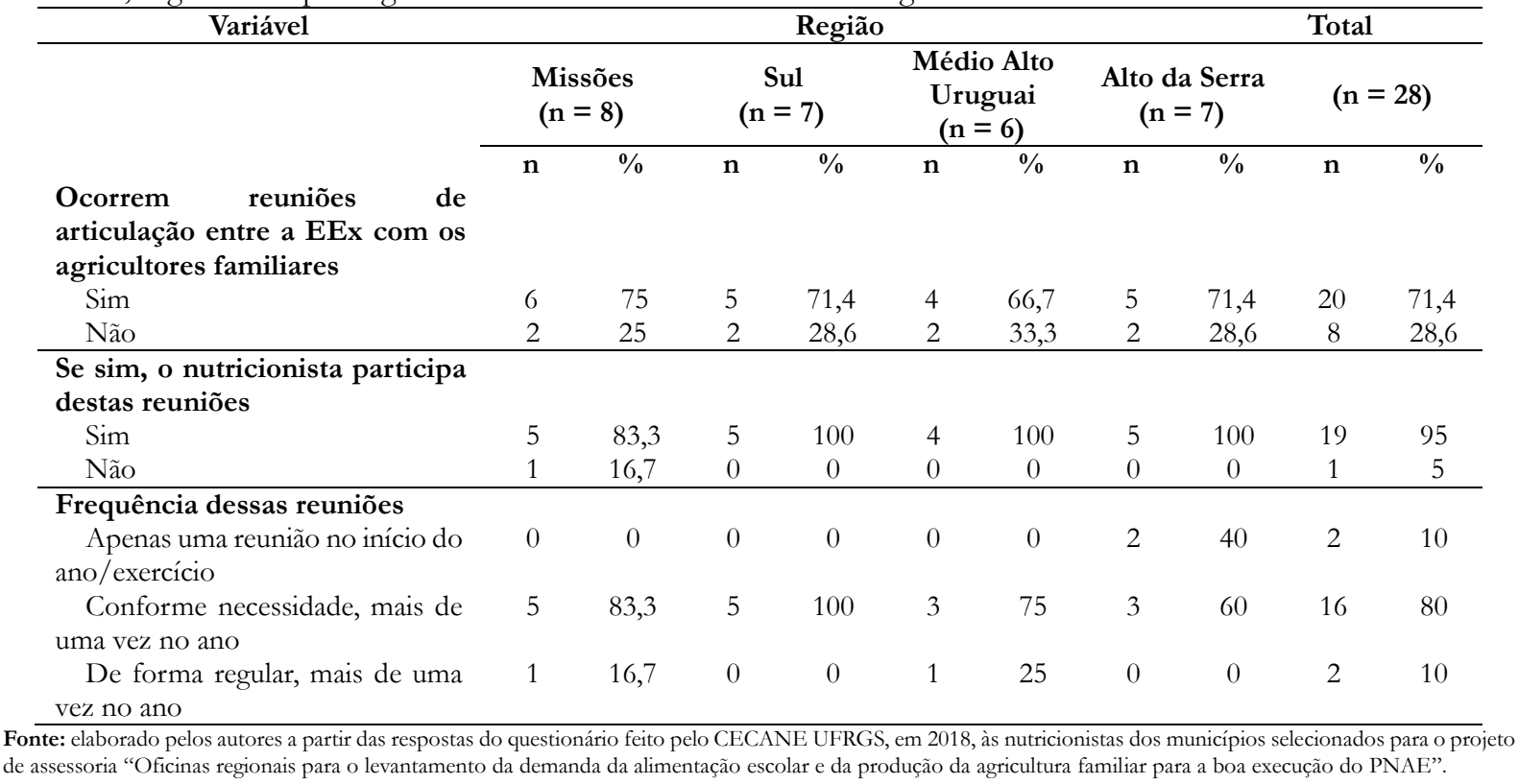

Constata-se que ocorrem reuniões de articulação entre a EEx e os agricultores familiares em $20(71,4 \%)$ municípios, sendo que os nutricionistas participam dessas reuniões em 19 (95\%) municípios. No manual do FNDE[55] com dez passos para a aquisição de produtos da $\mathrm{AF}$, a articulação entre os atores sociais é o segundo passo, imprescindível para efetuar o mapeamento dos produtos da AF e avaliar possibilidades de produção com os agricultores. A participação do nutricionista é considerada fundamental para a elaboração dos cardápios conforme a oferta da $\mathrm{AF}$, que definirá a pauta de compras para os editais de chamada pública. Salienta-se que o referido manual foi elaborado em 2016, portanto seu conteúdo precisa ser atualizado com a legislação vigente, todavia, a apresentação das etapas para as compras da AF segue sendo uma boa referência para a organização das EEx.

Segundo as nutricionistas, na maioria dos municípios que fazem reunião com a $\mathrm{AF}(\mathrm{n}=16$, $80 \%$ ), a frequência das reuniões é determinada conforme necessidade, mais de uma vez por ano; em $2(10 \%)$ municípios ocorre apenas uma reunião no início do ano/exercício, e em outros dois (10\%) municípios as reuniões são realizadas de forma regular, mais de uma vez ao ano. Apesar de não haver regras, especula-se que a realização de reuniões mais frequentes pode favorecer a contemplação da sazonalidade nos cardápios e nas compras, bem como o desenvolvimento de estratégias para viabilizar o aumento e a diversificação da produção e da compra da AF local/regional, visto que, conforme Triches e Kilian[56], uma maior proximidade entre os atores e a boa comunicação pode facilitar a ação conjunta para a inclusão da AF local no PNAE. Os assuntos discutidos nessas reuniões são: produtos disponíveis (citado por 16 das 19 nutricionistas que participam das reuniões; 78,9\%), cronograma e logística de entrega $(n=13 ; 68,4 \%)$, qualidade dos alimentos $(n=7 ; 36,8 \%)$, quantidades a serem compradas $(n=5)$, preços/pagamento $(n=5,26,3 \%)$, elaboração de cardápios $(\mathrm{n}=2,10,5 \%)$, incentivo à produção agrícola e agroindústrias $(n=1,5,3 \%)$, alimentação saudável nas escolas $(n=1,5,3 \%)$, possibilidade de cultivo de novos produtos $(\mathrm{n}=1$, $5,3 \%)$, aceitabilidade dos alunos $(n=1,5,3 \%)$, falta de rotatividade de culturas $(n=1,5,3 \%)$, divisão de responsabilidades no fornecimento da alimentação escolar $(n=1,5,3 \%)$, futuras chamadas públicas $(n=1$, $5,3 \%)$ e prestação de contas $(n=1,5,3 \%)$. 
$\mathrm{Na}$ Tabela 4 são apresentadas as opiniões dos nutricionistas sobre a importância da AF nos seus municípios.

Tabela 4. Opinião das nutricionistas sobre a agricultura familiar nos municípios selecionados, em números absolutos e percentuais, organizados por região do Rio Grande do Sul e total das regiões. Dados de 2018.

\begin{tabular}{|c|c|c|c|c|c|c|c|c|c|c|}
\hline \multirow[t]{3}{*}{ Variável } & \multicolumn{7}{|c|}{ Região } & \multicolumn{3}{|c|}{ Total } \\
\hline & \multicolumn{2}{|c|}{$\begin{array}{l}\text { Missões } \\
(n=8)\end{array}$} & \multicolumn{2}{|c|}{$\begin{array}{c}\text { Sul } \\
(n=7)\end{array}$} & \multicolumn{2}{|c|}{$\begin{array}{l}\text { Médio Alto } \\
\text { Uruguai } \\
(n=6)\end{array}$} & \multicolumn{2}{|c|}{$\begin{array}{l}\text { Alto da Serra } \\
\qquad(\mathrm{n}=7)\end{array}$} & \multicolumn{2}{|c|}{$(n=28)$} \\
\hline & $\mathrm{n}$ & $\%$ & $\mathrm{n}$ & $\%$ & $\bar{n}$ & $\%$ & $\mathrm{n}$ & $\%$ & $\mathrm{n}$ & $\%$ \\
\hline Importância da Agricultura & & & & & & & & & & \\
\hline \multicolumn{11}{|l|}{$\begin{array}{l}\text { Familiar no desenvolvimento do } \\
\text { município }\end{array}$} \\
\hline Nada ou pouco importante & 0 & 0 & 1 & 14,3 & 0 & 0 & 0 & 0 & 1 & 3,6 \\
\hline Importante & 0 & 0 & 0 & 0 & 0 & 0 & 1 & 14,3 & 1 & 3,6 \\
\hline Muito importante & 8 & 100 & 6 & 85,7 & 6 & 100 & 6 & 85,7 & 26 & 92,8 \\
\hline \multirow{3}{*}{\multicolumn{11}{|c|}{$\begin{array}{lcr}\text { Importância da compra } & \text { da } \\
\text { Agricultura } & \text { Familiar } & \text { para } \\
\text { alimentação escolar } & \end{array}$}} \\
\hline & & & & & & & & & & \\
\hline & & & & & & & & & & \\
\hline Nada ou pouco importante & 0 & 0 & 0 & 0 & 0 & 0 & 0 & 0 & 0 & 0 \\
\hline Importante & 0 & 0 & 0 & 0 & 0 & 0 & 0 & 0 & 0 & 0 \\
\hline Muito importante & 8 & 100 & 7 & 100 & 6 & 100 & 7 & 100 & 28 & 100 \\
\hline \multicolumn{11}{|l|}{ 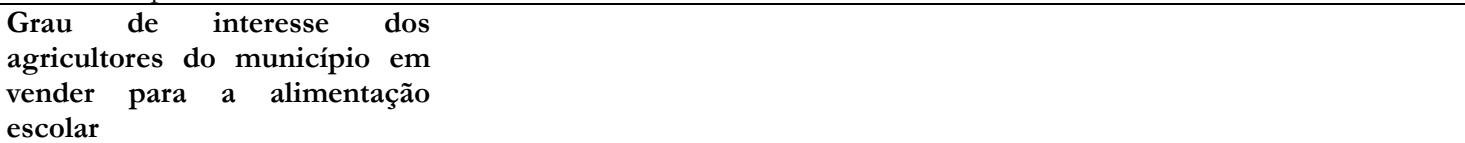 } \\
\hline Nenhum interesse & 1 & 12,5 & 1 & 14,3 & 0 & 0 & 1 & 14,3 & 3 & 10,7 \\
\hline Baixo interesse & 0 & 0 & 3 & 42,8 & 0 & 0 & 2 & 28,6 & 5 & 17,8 \\
\hline Interesse & 3 & 37,5 & 1 & 14,3 & 5 & 83,3 & 3 & 42,8 & 12 & 42,8 \\
\hline Alto interesse & 4 & 50 & 2 & 28,6 & 1 & 16,7 & 1 & 14,3 & 8 & 28,6 \\
\hline
\end{tabular}

\begin{tabular}{|c|c|c|c|c|c|c|c|c|c|c|}
\hline \multicolumn{11}{|c|}{$\begin{array}{l}\text { Percentual de compra de } \\
\text { gêneros da agricultura familiar } \\
\text { para a alimentação escolar que o } \\
\text { município deveria e/ou teria } \\
\text { potencial de atingir }\end{array}$} \\
\hline Menos que $30 \%$ & 0 & 0 & 1 & 14,3 & 3 & 50 & 2 & 28,6 & 6 & 21,4 \\
\hline Entre $30 \%$ e $50 \%$ & 7 & 87,5 & 5 & 71,4 & 3 & 50 & 4 & 57,1 & 19 & 67,9 \\
\hline Entre 51 e $75 \%$ & 1 & 12,5 & 1 & 14,3 & 0 & 0 & 1 & 14,3 & 3 & 10,7 \\
\hline Mais que $75 \%$ & 0 & 0 & 0 & 0 & 0 & 0 & 0 & 0 & 0 & 0 \\
\hline
\end{tabular}

A maioria das nutricionistas ( $\mathrm{n}=27,96,4 \%$ ) classificou a importância da AF no desenvolvimento dos municípios como importante ou muito importante. Já em relação à importância da compra da AF para a alimentação escolar, todas as nutricionistas julgaram ser muito importante.A percepção que um ator do PNAE tem sobre a importância da AF para a alimentação e para o desenvolvimento local é a base de sua motivação e dedicação à causa. Por isso, é essencial que os nutricionistas tenham conhecimento sobre os benefícios nutricionais, sociais, ambientais e econômicos desses alimentos. Dessa forma, os nutricionistas do PNAE também podem contar com argumentos para sensibilizar os gestores e demais atores do PNAE para a importância da aquisição dos produtos da AF, uma vez que, conforme colocado por Assis et al.[31], em algumas EEx, o percentual mínimo desse tipo de compra é visto como mera "obrigação", sem reconhecimento dos seus benefícios para o desenvolvimento rural, local e para a segurança alimentar e nutricional do alunado e do município. Assim, ressalta-se a necessidade da formação acadêmica em nutrição abordar o PNAE e 
questões sobre o sistema agroalimentar, modos de produção, alimentos regionais e da sociobiodiversidade, sempre pautadas na perspectiva da SAN e do DHAA[57,58]. Também se destaca a importância do FNDE prestar informações, capacitações e recursos suficientes para a execução das exigências normativas do PNAE, a fim de preparar os servidores públicos para sua operacionalização[31]. Os CECANE e EMATER locais podem auxiliar nessas ações.

Quanto ao grau de interesse dos agricultores do município em vender para a alimentação escolar, 12 nutricionistas $(42,8 \%)$ referiram que os agricultores possuem interesse, 8 (28,6\%) responderam alto interesse e $5(17,8 \%)$ e $3(10,7 \%)$, consideraram baixo e nenhum interesse, respectivamente. Alguns artigos sobre compras da AF para o PNAE mencionam a falta de interesse de agricultores familiares nesse mercado como um entrave para o cumprimento da legislação ${ }^{[2,59,31]}$. Assis et al. [31], ao analisarem o acesso da AF ao PNAE em três municípios mineiros, citam casos de desinteresse de agricultores por diversos motivos: por possuírem produção insuficiente para a demanda (seja por falta de recursos, estrutura ou mão de obra); por considerarem os preços a serem pagos ruins (às vezes, as EEx não consideram o preço adicional de embalagens ou frete, especialmente importante quando a distância entre produtores e escolas é longa[ $\left.{ }^{[00]}\right)$; por dificuldade em mensurar quanto produzir e quanto vender; por preocupação quanto ao recebimento/atraso do pagamento; pela burocracia para ingressar no programa. Além disso, os autores do artigo lembram que nem todos os agricultores conhecem o PNAE e que, entre os que conhecem, é comum que tenham incertezas sobre seu funcionamento. Assim, Assis et al.[31] evidenciam a importância da organização e atuação de associações de agricultores e da extensão rural, bem como do envolvimento das EEx, a fim de informar e prestar apoio aos agricultores quanto à participação no PNAE. Olhando para as responsabilidades das EEx, Triches e Silvestri[ ${ }^{[61]}$ argumentam que a redação das chamadas públicas deve apresentar detalhes sobre quantidade e qualidade dos alimentos, logística, periodicidade de entrega e preços a serem pagos, visto que essas informações são essenciais para o interesse e organização dos agricultores para que consigam ofertar os alimentos de forma regular. Por fim, para que os agricultores familiares participem das chamadas públicas, a escolha dos alimentos demandados deve estar alinhada com a sua produção e sazonalidade [31]. Para tanto, os nutricionistas precisam conhecer essa produção local para inserir tais alimentos nos cardápios e nas chamadas públicas. Por isso é importante a participação desse profissional em reuniões com a EMATER, organizações da agricultura familiar e equipe do setor de compras da EEx, para que auxilie na redação das chamadas públicas (em especial nas especificações e quantitativos dos alimentos e na periodicidade de entrega), bem como para que converse, quando for o caso, sobre a possibilidade dos agricultores diversificarem sua produção.

Ao serem questionadas sobre o percentual de compras da AF que seu município deveria e/ou teria potencial de atingir, $19(67,9 \%)$ nutricionistas acreditam que seria entre $30 \%$ e $50 \%$; seis nutricionistas $(21,4 \%)$ indicaram menos que $30 \%$; e três $(10,7 \%)$ nutricionistas consideram possível alcançar entre $51 \%$ e $75 \%$. Ou seja, a maioria das nutricionistas, 22 (78,6\%), acha que é praticável, em suas realidades, ultrapassar o mínimo estipulado pela legislação para compra da AF. Este é um dado que merece maior investigação, visto que pressupõe que existem barreiras transponíveis para aumentar as aquisições nos municípios. Infelizmente, a pergunta do questionário contemplava somente a opinião das nutricionistas, não solicitando justificativa.

Triches e Kilian ${ }^{[56]}$, ao estudarem o papel dos atores sociais nas aquisições de alimentos da $\mathrm{AF}$ para o PNAE, indicam que experiências bem sucedidas têm em comum a presença de relações sociais mais próximas entre os diversos atores do PNAE (gestores, nutricionistas, funcionários das escolas, extensionistas rurais, agricultores familiares e suas organizações, CAE, entre outros), com fácil diálogo e agência. Ou seja, para implementar a lei, não basta que os atores tenham conhecimento sobre a importância da inclusão da AF no PNAE: é necessário que se mobilizem enquanto agentes sociais para gerar mudanças nos espaços de sua responsabilidade e superar desafios ${ }^{[6]}$. Balestrin ${ }^{[62]}$ apresenta o caso de um município em que a nutricionista foi facilitadora do processo de compras da AF, auxiliando na divulgação dos prazos, na orientação sobre a parte burocrática e na elaboração dos projetos. Apesar da articulação direta para elaboração das chamadas públicas não ser 
responsabilidade desse profissional, esse caso é um exemplo do poder de agência dos nutricionistas do PNAE, que ao reconhecerem e se comprometerem com a importância das compras da AF, podem mobilizar e auxiliar outras pessoas para viabilizar as aquisições.

Frente a essas discussões, cabe refletir também sobre o atual período de pandemia de COVID-19, em que o FNDE manteve os repasses de recursos do PNAE para as EEx, bem como a recomendação dos $30 \%$ para as compras da AF[25,26,27]. Em 2020, enquanto as aulas estavam suspensas, foi orientada a distribuição de kits de alimentos para os alunos. Com o retorno das aulas em ensino híbrido em 2021, os alunos em aula presencial estão recebendo a alimentação nas escolas, enquanto os alunos que ficam em casa podem receber kits de alimentos. É importante frisar que a distribuição de kits não é obrigatória, ficando a critério da organização de cada EEx. Contudo, em um cenário de crise econômica, com aumento do desemprego e da insegurança alimentar no Brasil[63], faz-se necessária a mobilização dos envolvidos com o PNAE para garantir o direito do acesso à alimentação escolar, especialmente aos alunos que dependem deste programa para ter uma alimentação adequada, cumprindo assim com o caráter do Programa de promoção da segurança alimentar e nutricional. A manutenção das compras da $\mathrm{AF}$ nesse período é fundamental para garantir renda para as famílias agricultoras e comida de qualidade para os alunos. Assim, os nutricionistas, enquanto responsáveis técnicos pela execução do PNAE, devem mobilizar as gestões municipais/estaduais para a importância da manutenção das compras da AF e da distribuição dos kits, buscando inclusive eventuais parcerias com outras secretarias, como a da assistência social, por exemplo, para viabilizar as entregas dos kits.

\section{CONSIDERAÇÕES FINAIS}

Este estudo buscou analisar e refletir sobre a atuação de nutricionistas do PNAE na viabilização das compras da AF, uma vez que este profissional é um agente chave nesse processo. É relevante, portanto, acompanhar o cumprimento de suas atribuições, identificando dificuldades enfrentadas e soluções adotadas ou possíveis.
De modo geral, a maioria das nutricionistas contatadas relatou desempenhar atribuições relacionadas à compra da AF no PNAE. No que compete à atuação desse profissional, foram observadas algumas situações que podem estar dificultando o processo de aquisição da $\mathrm{AF}$ nos municípios: QT de nutricionistas insuficiente; falta de acesso ao mapeamento agrícola da região; ausência no processo de compras ou participação pouco ativa; falta de articulação com outros atores do PNAE, agricultores e suas organizações e instituições de apoio como EMATER e Secretaria da Agricultura; falta de compreensão sobre a importância da AF para o município.

Frente a essa análise, ressalta-se a importância da contratação de nutricionistas em número e carga horária de trabalho conforme os parâmetros indicados na Resolução CFN no $465 / 2010$, visando à realização adequada de suas atribuições. Adicionalmente, é importante que esses profissionais sejam devidamente capacitados para viabilizar as compras da agricultura familiar, sendo que o CECANE e a EMATER são instituições que podem ser contatadas para ajudar nesse sentido. A formação acadêmica dos nutricionistas também seria beneficiada com currículos que dediquem maior atenção ao PNAE e conteúdos sobre sistemas agroalimentares na perspectiva da SAN e do DHAA.

Como limitações do presente estudo, destaca-se que foram contemplados somente nutricionistas de municípios do RS que não atingiam a meta de compras proposta na Lei no 11.947/2009. Além disso, as perguntas dos questionários não permitiram um detalhamento sobre a qualidade da execução das atividades realizadas, mas permitiram ter uma ideia sobre o que acontece nos municípios. Seria pertinente realizar uma pesquisa mais detalhada, analisando também a atuação de nutricionistas de municípios que atingem ou ultrapassam os 30\% de investimento, a fim de realizar comparações. Também lembramos que os questionários foram enviados por e-mail, sendo as respostas suscetíveis à interpretação pessoal dos respondentes.

Os resultados deste trabalho são importantes para auxiliar no delineamento de planos de ação para o aperfeiçoamento contínuo da execução do PNAE. Em vista da complexidade da 
realidade de cada município (articulação política, engajamento social, panorama agrícola), seria útil aprofundar o diagnóstico da atuação de outros atores envolvidos com as compras do PNAE a nível local para analisar se trabalham de forma alinhada e construtiva ou se apresentam dificuldades de articulação e quais seriam. Por fim, enfatiza-se a escassez de estudos que avaliam a atuação do nutricionista em suas atribuições especificamente no processo de compras da $\mathrm{AF}$, tanto na região de estudo quanto no Brasil, necessitando mais trabalhos que analisem esta relação.

\section{REFERÊNCIAS}

[1] Peixinho AML. A trajetória do Programa Nacional de Alimentação Escolar no período de 2003-2010: relato do gestor nacional. Cien. Saude Colet. 2013;18(4):909-916.

[2] Saraiva EB, Silva APF, Souza AA, Cerqueira GF, Chagas CMS, Toral N. Panorama da compra de alimentos da agricultura familiar para o Programa Nacional de Alimentação Escolar. Cien Saude Colet. 2013;18(4):927935.

[3] Brasil. Ministério da Educação. Fundo Nacional de Desenvolvimento da Educação. PNAE, Sobre o Programa, Histórico [Internet]. 2017 [acesso em 2018 nov 03]. Disponível em: http://www.fnde.gov.br

[4] Brasil. Ministério da Educação. Fundo Nacional de Desenvolvimento da Educação. Resolução no 06, de 08 de maio de 2020. Dispõe sobre o atendimento da alimentação escolar aos alunos da educação básica no âmbito do Programa Nacional de Alimentação Escolar - PNAE. Diário Oficial da União; 2020.

[5] Brasil. Ministério da Saúde. Secretaria de Atenção Básica. Departamento de Atenção Básica. Guia alimentar para a população brasileira. 2.ed. Brasília: Ministério da Saúde; 2014.

[6] Brasil. Ministério da Educação. Fundo Nacional de Desenvolvimento da Educação. Acesso à Informação, Ações e Programas, Programas, PNAE, Consultas, Dados Físicos e Financeiros do PNAE [Internet]. 2021 [acesso em 2021 nov 20]. Disponível em: https://www.gov.br/fnde

[7] Brasil. Lei no 11.947 de 16 de junho de 2009. Dispõe sobre o atendimento da alimentação escolar e do Programa Dinheiro Direto na Escola aos alunos da educação básica. Diário Oficial da União; 2009.
[8] Gregolin GC, Gregolin MRP, Triches RM, Zonin WJ. Inserção da agricultura familiar no Programa Nacional de Alimentação Escolar (PNAE): estratégia de segurança alimentar e nutricional sustentável. Perspectiva. 2018;42(159):45-57.

[9] Priore SE, Trivellato PT, Lopes SO, de Assis SCR, Costa BAL, Franceschini SCCF, Santos RHS. Comercialização da agricultura familiar no desenvolvimento da segurança alimentar e nutricional. [Internet]. 2021 [acesso em 2021 ago 30]. Disponível em: https://www.ippds.ufv.br/producoes

[10] Brasil. Lei no 11.346, de 15 de setembro de 2006. Cria o Sistema Nacional de Segurança Alimentar e Nutricional - SISAN com vistas em assegurar o direito humano à alimentação adequada e dá outras providências. Diário Oficial da União; 2006.

[11] Brasil. Câmara Interministerial de Segurança Alimentar e Nutricional. II Plano Nacional de Segurança Alimentar e Nutricional: PLANSAN 2016-2019. Brasília: CAISAN; 2018.

[12] Brasil. Ministério da Educação. Fundo Nacional de Desenvolvimento da Educação. Resolução no 26, de 17 de junho de 2013. Dispõe sobre o atendimento da alimentação escolar aos alunos da educação básica no âmbito do Programa Nacional de Alimentação Escolar PNAE. Diário Oficial da União; 2013.

[13] FAO. WFP. Home-Grown School Feeding. Resource Framework. Technical Document. [Internet]] 2018 [acesso em 2021 ago 30]. Disponível em: https://www.wfp.org/publications/home-grown-schoolfeeding-resource-framework

[14] Triches RM, Schneider S. Reconstruindo o "elo perdido": a reconexão da produção e do consumo de alimentos através do Programa de Alimentação Escolar no município de Dois Irmãos (RS). Segur. Aliment. Nutr. 2010;17(1):1-15.

[15] Brasil. Ministério da Educação. Fundo Nacional de Desenvolvimento da Educação. PNAE, Consultas, Dados da Agricultura Familiar [Internet]. 2017 [acesso em 2019 nov 25]. Disponível em: http://www.fnde.gov.br

[16] Brasil. Conselho Federal de Nutricionistas. Resolução/CFN no 465 de 23 de agosto de 2010. Dispõe sobre as atribuições do Nutricionista, estabelece parâmetros numéricos mínimos de referência no âmbito do Programa de Alimentação Escolar (PAE) e dá outras providências. Diário Oficial da União; 2010. 
[17] Chaves LG, Santana TCM, Gabriel CG, Vasconcelos FDAG. Reflexões sobre a atuação do nutricionista no Programa Nacional de Alimentação Escolar no Brasil. Cien. Saude Colet. 2013;18(4):917-926.

[18] Corrêa RS, Rockett FC, Rocha PB, da Silva VL, Oliveira VR. Atuação do Nutricionista no Programa Nacional de Alimentação Escolar na Região Sul do Brasil. Cien. Saude Colet. 2017;22(2):563-574.

[19] Gabriel CG, Goulart G, Calvo MC. Gestão municipal do Programa Nacional de Alimentação Escolar nas capitais da região Sul do Brasil. Rev. Nut. 2015;28(6):667680.

[20] Machado PMO, Machado MS, Schmitz BAS, Corsa ACT, González-Chica DA, Vasconcelos FAG. Caracterização do Programa Nacional de Alimentação Escolar no Estado de Santa Catarina. Rev. Nutr. 2013;26(6):715-725.

[21] Ferreira DM, Barbosa RMS, Finizola NC, Soares DSB, Henriques P, Pereira S, Carvalhosa CS, Siqueira ABFS, Dias PC. Percepção de agentes operadores do Programa Nacional de Alimentação Escolar. Rev. Saude Publica. 2019;53:34.

[22] Leão PV, Cabral BC, Dias IA, Carneiro LMA, Frazão AGF. Atribuições do nutricionista no Programa Nacional de Alimentação Escolar. Agricultura Familiar: Pesquisa, Formação e Desenvolvimento. 2021;15(1):57-74.

[23] Henkel K. A categorização e a validação das respostas abertas em surveys políticos. Opin. Pública. 2017;23(3):786-808.

[24] Brasil. Ministério da Educação. Fundo Nacional de Desenvolvimento da Educação (FNDE). Alunado por ação do Programa Nacional de Alimentação Escolar. [Internet]. 2018 [acesso em 2018 nov 15]. Disponível em: http://www.fnde.gov.br/pnaeweb

[25] Brasil. Ministério da Educação. Fundo Nacional de Desenvolvimento da Educação. Resolução no -2 , de 09 de abril de 2020. Dispõe sobre a execução do Programa Nacional de Alimentação Escolar - PNAE durante o período de estado de calamidade pública, reconhecido pelo Decreto Legislativo no 6, de 20 de março de 2020, e da emergência de saúde pública de importância internacional decorrente do novo coronavírus - Covid-19. Diário Oficial da União; 2020.

[26] Brasil. Ministério da Agricultura, Pecuária e Abastecimento. Ministério da Educação. Orientações para a execução do PNAE durante a situação de emergência decorrente da pandemia do coronavírus (covid-19) [Internet]. 2020 [acesso em 2021 ago 02]. Disponível em: https://www.fnde.gov.br/index.php/programas/pnae/p nae-area-gestores/pnae-manuais-cartilhas

[27] Brasil. Fundo Nacional de Desenvolvimento da Educação. Recomendações para a execução do Programa Nacional de Alimentação Escolar no retorno presencial às aulas durante a pandemia da Covid-19: educação alimentar e nutricional e segurança dos alimentos [Internet]. 2020 [acesso em 2021 ago 02] Disponível em: https://www.fnde.gov.br/index.php/programas/pnae/p nae-area-gestores/pnae-manuais-cartilhas

[28] Machado PMO, Schmitz BAS, González-Chica DA, Corso ACT, Vasconcelos FAG, Gabriel CG. Compra de alimentos da agricultura familiar pelo Programa Nacional de Alimentação Escolar (PNAE): estudo transversal com o universo de municípios brasileiros. Cien. Saude Colet. 2018;23(12):4153-4164.

[29] De Sousa AA, da Silva APF, de Azevedo E, Ramos MO. Cardápios e sustentabilidade: ensaio sobre as diretrizes do Programa Nacional de Alimentação Escolar. Rev. Nutr. 2015;28(2):217-229.

[30] Gazolla M. Segurança alimentar e nutricional e agroindústrias familiares: políticas públicas e ações locais. Segur. Aliment Nutr. 2014;21(2):527-540.

[31] Assis TRP, França AGM, Coelho AM. Agricultura familiar e alimentação escolar: desafios para o acesso aos mercados institucionais em três municípios mineiros. Rev. Econ. Sociol. Rural. 2019;57(4):577-593.

[32] Chaves LG, Mendes PNR, de Brito RR, Botelho, RBA. O programa nacional de alimentação escolar como promotor de hábitos alimentares regionais. Rev. Nutr. 2009;22(6):857-866.

[33] Girardi MW, Fabri RK, Bianchini VU, Martinelli SS, Cavalli SB. Oferta de preparações culinárias e alimentos regionais e da sociobiodiversidade na alimentação escolar: um estudo na Região Sul do Brasil. Segur. Aliment Nutr. 2018;25(3)29-44.

[34] Fabri RK, Proença RPC, Martinelli SS, Cavalli SB. Regional foods in Brazilian school meals. BFJ. 2015;117(6):1706-1719.

[35] Brasil. Ministério do Desenvolvimento Social e Combate à Fome. Marco de referência de educação alimentar e nutricional para as políticas públicas. Brasília: 
Secretaria Nacional de Segurança Alimentar e Nutricional; 2012.

[36] Díaz S, Settele J, Brondízio ES, Ngo HT, Guèze M et al. IPBES: Summary for policymakers of the global assessment report on biodiversity and ecosystem services of the Intergovernmental Science-Policy Platform on Biodiversity and Ecosystem Services. Bonn, Germany: IPBES Secretariat; 2019.

[37] Hunter D, Gee E, Borelli T. Nourishing people, nurturing the environment: Biodiversity for food systems transformation and healthier diets. In: Hunter D, Borelli T, Gee E. Biodiversity, food and nutrition: a new agenda for sustainable food systems. New York: Routledge; 2020. p. 03-20.

[38] Coradin L, Siminski A, Reis A. Espécies nativas da flora brasileira de valor econômico atual ou potencial. Plantas para o futuro - Região Sul. Brasília: Ministério do Meio Ambiente; 2011.

[39] Hawkes C, Friel S, Lobstein T, Lang T. Linking agricultural policies with obesity and noncommunicable diseases: A new perspective for a globalising world. Food Policy. 2012;37(3):343-353.

[40] Global Panel on Agriculture and Food Systems for Nutrition. Future Food Systems: for people, our planet and prosperity [Internet]. 2020 [Acesso em 2021 ago 30]. Disponível em: https:/ / foresight.glopan.org/

[41] Lang T, Heasman M. Food Wars: The battle for minds, mouths and markets. London: Earthscan; 2015.

[42] Swinburn B, Kraak VI, Allender S, Atkins VJ, Baker PI et al. The Global Syndemic of Obesity, Undernutrition, and Climate Change: The Lancet Commission report. Lancet. 2019;393(10173):791-846.

[43] Dal Soglio FK. A agricultura moderna e o mito da produtividade. In: Dal Soglio FK, Kubo RR. Desenvolvimento, Agricultura e Sustentabilidade. Porto Alegre: UFRGS; 2016. p. 11-38.

[44] FAO. The State of the World's Biodiversity for Food and Agriculture [Internet] 2019 [acesso em 2021 ago 30]. Disponível http://www.fao.org/3/CA3129EN/CA3129EN.pdf

[45] Santiago RAC, Coradin L. Biodiversidade brasileira: sabores e aromas [Internet]. 2018 [acesso em 2019 out 25]. Brasília: MMA (Série Biodiversidade; 52). Disponível em: http://www.mma.gov.br/publicacoes/biodiversidade/cat egory/142-serie-biodiversidade.html

[46] Brasil. Ministério do Desenvolvimento Agrário. Plano Nacional de Promoção das Cadeias de Produtos da Sociobiodiversidade. Brasília: Ministério do Desenvolvimento Agrário; 2009.

[47] Hendler VM, Ruiz ENF, Oliveira LD. Sociobiodiversidade na escola, promoção da saúde, da sustentabilidade e da cultura: um movimento em construção no município de Mostardas/RS. Agricultura Familiar: Pesquisa, Formação e Desenvolvimento. 2021;15(1):115-134.

[48] Brito TP, Rocha LCD, Hirata AR, Raimundo RRF, Galvão LO. A valorização da sociobiodiversidade na alimentação escolar. Segur. Aliment. Nutr. 2020;27:1-13. e020030.

[49] Brasil. Portaria Interministerial MAPA/MMA no 10, de 21 de julho de 2021. Institui lista de espécies nativas da sociobiodiversidade de valor alimentício, para fins de comercialização in natura ou de seus produtos derivados [Internet]. 2021 [acesso em 2021 ago 02]. Diário Oficial da União; 2021. Disponível em: https://in.gov.br

[50] Kinupp VF, Lorenzi H. Plantas Alimentícias NãoConvencionais (PAN'C) no Brasil: guia de identificação, aspectos nutricionais e receitas ilustradas. Nova Odessa: Ed. Plantarum; 2014.

[51] Bezerra OMPA, Bonomo E, Silva CAM, Correa MS, Souza AA et al. Promoção da aquisição de produtos da agricultura familiar para a alimentação escolar em Territórios da Cidadania de Minas Gerais e Espírito Santo. Rev. Nutr. 2013;26(3):335-342.

[52] Becker C, Andersson FS, Altemburg SGN, Costa LC. Novas concertações sociais e antigos entraves "burocráticos": a produção de base familiar e ecológica frente aos desafios de acesso ao PNAE. Cad. Agroecol. $2011 ; 6(2)$.

[53] Teo CRPA, Motter AF, Barbosa LP, Dacroce M, Pagliarini G. Articulação entre agricultura familiar e alimentação escolar em municípios de pequeno porte. Campo-Território: revista de geografia agrária. 2016;11(24):175-199.

[54] Alexandre VP, Gomes LOF, Silva SU, Almeida GM, Martins KA et al. Do campo à escola: compra de alimentos da agricultura familiar pelo Programa Nacional de 
Alimentação Escolar em Territórios da Cidadania de Goiás. Segur. Aliment. Nutr. 2016;23:1049-1064.

[55] Brasil. Ministério da Educação. Fundo Nacional de Desenvolvimento da Educação. Aquisição de produtos da agricultura familiar para a alimentação escolar. 3 ed. Brasília: FNDE; 2017.

[56] Triches RM, Kilian L. Papel dos atores sociais na aquisição de produtos da agricultura familiar para alimentação em municípios paranaenses. Redes (St. Cruz Sul, Online). 2016;21(3):159-179.

[57] Redin C. Agrobiodiversidade e a sua articulação entre as dimensões da Segurança Alimentar e Nutricional: uma análise multiescalar no Território Rural Campos de Cima da Serra, Rio Grande do Sul. 2017 [dissertação]. Porto Alegre: Universidade Federal do Rio Grande do Sul; 2017.

[58] Recine E, Gomes RCF, Fagundes AA, Pinheiro ARO, Teixeira BA et al. A formação em saúde pública nos cursos de graduação de nutrição no Brasil. Rev. Nutr. 2012;25(1):21-33.

[59] Ferigollo D, Kirsten VR, Heckler D, Figueredo OAT, Perez-Cassarino J, Triches RM. Aquisição de produtos da agricultura familiar para alimentação escolar em municípios do Rio Grande do Sul. Rev. Saude Publica. 2017;51:6.

[60] Torres FL, Torres ACM, Sobrinho F, Dias TF, Nunes EM. Inserção da agricultura familiar sustentável no PNAE: o caso da COOPAPI, Apodi - RN. Cadernos de Agroecologia. 2011;6(2):1-6.

[61] Triches RM, Silvestri F. Adequação das chamadas públicas para aquisição de produtos da agricultura familiar para a alimentação escolar. Desenvolvimento em Questão. 2018;16(44):233-259.

[62] Balestrin ELB. As estratégias de inserção dos agricultores familiares no programa de alimentação escolar de Capitão Leônidas Marques [dissertação]. Pato Branco: Universidade Tecnológica do Paraná; 2014.

[63] Penssan R. Rede Brasileira de Pesquisa em Soberania e Segurança Alimentar. VIGISAN: Inquérito Nacional sobre Insegurança Alimentar no Contexto da Pandemia da Covid-19 no Brasil [Internet]. 2021 [acesso em 2021 ago 30]. Disponível em: http://olheparaafome.com.br 